\title{
An optimal inverse method using Doppler lidar measurements to estimate the surface sensible heat flux
}

Article

Accepted Version

Author's file corrected copy edits

Dunbar, T. M., Barlow, J. F. and Belcher, S. E. (2013) An optimal inverse method using Doppler lidar measurements to estimate the surface sensible heat flux. Boundary-Layer Meteorology, 150 (1). pp. 49-67. ISSN 0006-8314 doi: https://doi.org/10.1007/s10546-013-9858-2 Available at https://centaur.reading.ac.uk/38569/

It is advisable to refer to the publisher's version if you intend to cite from the work. See Guidance on citing.

Published version at: http://dx.doi.org/10.1007/s10546-013-9858-2

To link to this article DOI: http://dx.doi.org/10.1007/s10546-013-9858-2

Publisher: Springer Netherlands

All outputs in CentAUR are protected by Intellectual Property Rights law, including copyright law. Copyright and IPR is retained by the creators or other copyright holders. Terms and conditions for use of this material are defined in the End User Agreement.

www.reading.ac.uk/centaur 
Central Archive at the University of Reading

Reading's research outputs online 


\section{Boundary-Layer Meteorology}

\section{An optimal inverse method using Doppler lidar measurements to estimate the surface sensible heat flux \\ --Manuscript Draft--}

\begin{tabular}{|c|c|}
\hline Manuscript Number: & BOUN-D-12-01277R2 \\
\hline Full Title: & $\begin{array}{l}\text { An optimal inverse method using Doppler lidar measurements to estimate the surface } \\
\text { sensible heat flux }\end{array}$ \\
\hline Article Type: & Research Article \\
\hline Keywords: & Convective boundary layer; Doppler lidar; Inverse methods; Surface energy balance \\
\hline Corresponding Author: & $\begin{array}{l}\text { J.F. Barlow } \\
\text { University of Reading } \\
\text { Reading, UNITED KINGDOM }\end{array}$ \\
\hline \multicolumn{2}{|l|}{$\begin{array}{l}\text { Corresponding Author Secondary } \\
\text { Information: }\end{array}$} \\
\hline Corresponding Author's Institution: & University of Reading \\
\hline \multicolumn{2}{|l|}{$\begin{array}{l}\text { Corresponding Author's Secondary } \\
\text { Institution: }\end{array}$} \\
\hline First Author: & Tyrone M Dunbar \\
\hline \multicolumn{2}{|l|}{ First Author Secondary Information: } \\
\hline \multirow[t]{3}{*}{ Order of Authors: } & Tyrone M Dunbar \\
\hline & J.F. Barlow \\
\hline & Stephen E Belcher \\
\hline \multicolumn{2}{|c|}{ Order of Authors Secondary Information: } \\
\hline Abstract: & $\begin{array}{l}\text { Inverse methods are widely used in various fields of atmospheric science. However, } \\
\text { such methods are not commonly used within the boundary-layer community, where } \\
\text { robust observations of surface fluxes are a particular concern. We present a new } \\
\text { technique for deriving surface sensible heat fluxes from boundary-layer turbulence } \\
\text { observations using an inverse method. Doppler lidar observations of vertical velocity } \\
\text { variance are combined with two well-known mixed-layer scaling forward models for a } \\
\text { convective boundary layer (CBL). The inverse method is validated using large-eddy } \\
\text { simulations of a CBL with increasing wind speed. The majority of the estimated heat } \\
\text { fluxes agree within error with the proscribed heat flux, across all wind speeds tested. } \\
\text { The method is then applied to Doppler lidar data from the Chilbolton Observatory, UK. } \\
\text { Heat fluxes are compared with those from a mast-mounted sonic anemometer. Errors } \\
\text { in estimated heat fluxes are on average } 18 \% \text {, an improvement on previous } \\
\text { techniques. However, a significant negative bias is observed (on average - } 63 \text { \%) that is } \\
\text { more pronounced in the morning. Results are improved for the fully-developed CBL } \\
\text { later in the day, which suggests that the bias is largely related to the choice of forward } \\
\text { model, which is kept deliberately simple for this study. Overall, the inverse method } \\
\text { provided reasonable flux estimates for the simple case of a CBL. Results shown here } \\
\text { demonstrate that this method has promise in utilizing ground-based remote sensing to } \\
\text { derive surface fluxes. Extension of the method is relatively straight-forward, and could } \\
\text { include more complex forward models, or other measurements. }\end{array}$ \\
\hline Response to Reviewers: & $\begin{array}{l}\text { This resubmission is responding to copy edits on BOUN-D-12-01277R1 emailed on } 10 \\
\text { July } 2013\end{array}$ \\
\hline
\end{tabular}


Noname manuscript No.

(will be inserted by the editor)

\title{
An optimal inverse method using Doppler lidar measurements to estimate the surface sensible heat flux
}

\author{
T. M. Dunbar • J. F. Barlow • S. E. \\ Belcher \\ 7 Received: date / Accepted: date
}

\begin{abstract}
Inverse methods are widely used in various fields of atmospheric science. However, such methods are not commonly used within the boundary-layer community, where robust observations of surface fluxes are a particular concern. We present a new technique for deriving surface sensible heat fluxes from boundarylayer turbulence observations using an inverse method. Doppler lidar observations of vertical velocity variance are combined with two well-known mixed-layer scaling forward models for a convective boundary layer (CBL). The inverse method is validated using large-eddy simulations of a CBL with increasing wind speed. The majority of the estimated heat fluxes agree within error with the proscribed heat flux, across all wind speeds tested. The method is then applied to Doppler lidar data from the Chilbolton Observatory, UK. Heat fluxes are compared with those from a mast-mounted sonic anemometer. Errors in estimated heat fluxes are on average $18 \%$, an improvement on previous techniques. However, a significant negative bias is observed (on average $-63 \%$ ) that is more pronounced in the morning. Results are improved for the fully-developed CBL later in the day, which suggests that the bias is largely related to the choice of forward model, which is kept deliberately simple for this study. Overall, the inverse method provided reasonable flux estimates for the simple case of a CBL. Results shown here demonstrate that this method has promise in utilizing ground-based remote sensing to derive surface fluxes. Extension of the method is relatively straight-forward, and could include more complex forward models, or other measurements.
\end{abstract}

Keywords Convective boundary layer $\cdot$ Doppler lidar $\cdot$ Inverse methods $\cdot$ Surface energy balance

J.F.Barlow

Department of Meteorology, University of Reading,

Reading, UK.

E-mail: j.f.barlow@reading.ac.uk 


\section{Introduction}

Inverse methods have widespread use throughout the atmospheric science community, with the fields of data assimilation and measurement retrieval from weather satellites perhaps being the most well-known application. However, such methods are not as commonly used with ground-based remote-sensing measurements, and are rare within the boundary-layer literature. Using inverse methods for smallscale applications would provide advantages: for example, the probabilistic basis of inverse modelling techniques provides well-defined errors in the results, and allows for many different measurements to be combined easily within the same model framework.

A recent example of small-scale application of an inverse method is Hogan (2007), who used a variational method to retrieve rainfall rates using measurements from a polarization radar. The variational method allowed for attenuation in the measurement to be corrected, and also enabled the identification and measurement of hail, which would previously have required a separate algorithm. There have also been attempts to assimilate Doppler lidar measurements of wind velocity and turbulence into more complex boundary-layer models. For example, Newsom and Banta (2004) used a four-dimensional data assimilation method with radial Doppler lidar measurements of wind-velocity fields and turbulence. Their aim was to provide datasets that could be used to verify large-eddy simulation (LES) results, in particular evaluating subgrid-scale turbulence parametrizations. Inverse modelling techniques have also been applied in atmospheric dispersion; Rudd et al. (2011) used a variational method to estimate the source strength and position of an atmospheric gas release as a possible tool in the case of accidental or malicious release.

In this work, we use an inverse retrieval method with a surface-based remotesensing instrument to demonstrate a method for measuring surface sensible heat flux. Measurement of heat flux is of importance as both input and verification for numerical models of varying temporal and spatial scales, from simulations of city-scale pollution dispersion to numerical weather prediction models. However, measurements of the surface heat flux suitable for these purposes have proven difficult, in particular when considering measurements made over heterogeneous surfaces. As Cleugh and Grimmond (2001) wrote when discussing energy exchange in heterogeneous landscapes: "A current challenge in boundary-layer meteorology is to provide, either through modelling or measurements, estimates of turbulent fluxes that are representative of large regions, areas of $10^{2}-10^{4} \mathrm{~km}^{2}$, where the landscape is inevitably characterised by considerable surface heterogeneity". More than a decade later, this issue still represents a problem.

The principal difficulty with making measurements of surface fluxes over heterogeneous surfaces, for example in urban areas, arises from the instruments typically used. These are traditionally surface-based point instruments such as the sonic anemometer. The low height at which such instruments are generally placed results in measurements that have a small source area. For example, the source area of a typical tower-based flux measurement (at 20-30 m) is between 0.01-1 $\mathrm{km}^{2}$ (Cleugh and Grimmond, 2001), and so the flux measurements are only representative at the street scale. The placement of instruments is a problem that has limited efforts to measure and interpret urban fluxes and the urban boundary 
layer, for the simple reason that it is practically difficult to place sufficiently tall measurement towers in busy cities (Roth, 2000).

An increasingly popular method to resolve this problem is the use of remotesensing instruments. These instruments are capable of making measurements over a range from hundreds of metres to tens of kilometres, and as such make measurements that are representative of much greater areas than those made by point instruments mounted near the surface. Until recently, the resolution and reliability of surface-based remote-sensing instruments could not match the performance of the traditional methods, but advances in remote-sensing technology over the last two decades mean that long-term, high-quality measurements of turbulence are now viable. Along with a reduction in cost and an increase in commercial availability, this has seen an increase in studies and campaigns seeking to take advantage of the benefits of remote-sensing instruments; in particular their range and their ability to observe a flow without disturbing it.

Engelbart et al. (2007) reviewed some of the most common methods of using remote sensing to determine profiles of turbulent fluxes (and by extension surface fluxes) using various instruments; sodars, radio acoustic sounding systems (RASS), wind-profiling radars and lidars. They divided the methods into two categories; direct and parametric. Direct methods, as is implied, involve directly measuring fluxes using the eddy-correlation technique or by measuring variances. They require a rapid scanning instrument, or multiple beams. Parametric methods utilize simple models that relate averaged profiles of different variables to the fluxes.

A good example of the use of a parametric method was originally suggested by Angevine et al. (1994). They made measurements of the vertical velocity variance $\left(\sigma_{w}^{2}\right)$ in a convective boundary layer $(\mathrm{CBL})$ using a wind-profiling radar, and then used mixed-layer similarity theory to relate these measurements to the surface sensible heat flux. The results using this method were compared to heat-flux measurements made with the eddy-correlation method using a sonic anemometer. Angevine et al. (1994) considered the results to be in good agreement, although there was significant scatter that they believed could be reduced through longer averaging times for the variance measurements. Their dataset was quite small, consisting of only 20 measurements, which has often been a limitation with studies using remote sensing measurements for determining surface fluxes. For example, Davis et al. (2008) successfully used a Doppler lidar to estimate surface sensible heat fluxes over Salford, Greater Manchester, but had only 12 data points.

The results of Angevine et al. (1994) are encouraging, however their method was limited by the instruments available to them at the time; the vertical range resolution of the wind-profiling radar used was $105 \mathrm{~m}$, and the lowest measured gate was centred at $150 \mathrm{~m}$. Also, the model they used to relate the vertical velocity variance to the surface sensible heat flux was based upon averaged measurements over a limited height range in the lower half of the boundary layer.

This paper presents a new technique for deriving surface sensible heat fluxes from boundary-layer turbulence observations using an inverse method. The method is applied to Doppler lidar observations of the profile of vertical velocity variance in a CBL. Firstly, the formalism of the inverse model and the treatment of errors is presented and secondly, the method is validated using a large-eddy simulation of a CBL with increasing values of wind shear. Well-known mixed-layer similarity theory results are used as forward models to relate variance profiles to heat flux. Thirdly, the method is applied to Doppler lidar observations over moderately het- 
erogeneous terrain and compared with sonic anemometer heat-flux measurements The inverse method allows for calculation of a well-defined error in the results, permitting a robust comparison.

\section{The optimal inverse method}

An optimal inverse method (e.g. Lorenc, 1986; Rodgers, 2000; Bannister, 2003) comprises of two main components: a set of measurements and some parameters to be determined. The physical processes that relate these components are represented by a forward model. Given a particular set of measurements, the forward model can be inverted to determine an 'optimal estimate' of the parameters. The method explicitly accounts for observational errors, and errors in the predicted parameters. This section introduces the derivation of the optimal inverse method, describes the formulation of the errors in both the measurements and the predicted parameters, and presents two potential forward models.

\subsection{The cost function}

Following Rodgers (2000), we first define the notation of the components of our problem. Measurements are represented by the measurement vector, $\mathbf{y}$, the parameters we wish to retrieve are represented by the state vector, $\mathbf{x}$, while the forward model is denoted by the function, $\mathbf{F}$. The relationship between the measurements and retrieved parameters can then be written

$$
\mathbf{y}=\mathbf{F}(\mathbf{x})+\boldsymbol{\epsilon},
$$

where $\boldsymbol{\epsilon}$ represents any error in $\mathbf{y}$.

It is assumed that the observations can be described by a Gaussian distribution, with an associated mean and variance. Bayes theorem can then be used to define a cost function, $\mathbf{J}$

$$
2 \mathbf{J}=(\mathbf{y}-\mathbf{F}(\mathbf{x}))^{T} \mathbf{R}^{-1}(\mathbf{y}-\mathbf{F}(\mathbf{x}))
$$

where $\mathbf{R}$ is the error covariance matrix (of size $n \times n$ ) for the measurements. If the errors in the measurements are independent, this matrix is diagonal, with offdiagonal elements equal to zero. In this study, we assume that we possess no a priori knowledge of the state vector. The cost function is then minimized to find the optimal estimate of the state vector, $\hat{\mathbf{x}}$, which is now considered.

\subsection{Finding the optimal estimate}

In Bayesian terms, the minimum of the cost function is the same as the maximum of the posterior probability distribution $P(\mathbf{x} \mid \mathbf{y})$, i.e. the most probable value of the state vector given a set of measurements. In reality, $P(\mathbf{x} \mid \mathbf{y})$ may be asymmetric and have multiple peaks, making a solution difficult to find. It is reasonable to 
assume $P(\mathbf{x} \mid \mathbf{y})$ to be Gaussian (Rodgers, 2000, p. 84), thus the mean value of the distribution will provide our best estimate.

To find the minimum of the cost function we equate the derivative of Eq. 2 to zero, resulting in the following equation that is solved for $\mathbf{x}$

$$
\nabla_{\mathbf{x}}(\mathbf{2 J})=-\left[\nabla_{\mathbf{x}} \mathbf{F}(\mathbf{x})\right]^{\mathbf{T}} \mathbf{R}^{-\mathbf{1}}[\mathbf{y}-\mathbf{F}(\mathbf{x})]=\mathbf{0} .
$$

Most inverse problems in the atmosphere can be described as moderately nonlinear i.e. the forward model is non-linear and the prior information does not have a Gaussian distribution, but the errors can be described using Gaussian statistics (Rodgers, 2000, p. 81). For a moderately non-linear forward model, the zero in the gradient of the cost function can be found using the Gauss-Newton iteration method, which for the equation $f(x)=0$ can be written: $x_{k+1}=x_{k}-f\left(x_{k}\right) / f^{\prime}\left(x_{k}\right)$, where $k$ represents the iterative step and in this case, $f(x)$ is the first derivative of the cost function (Rodgers, 2000, p. 85). The iterative formula is then

$$
\mathbf{x}_{k+1}=\mathbf{x}_{k}+\mathbf{A}^{-\mathbf{1}}\left(\left(\mathbf{F}^{\prime}\left(\mathbf{x}_{k}\right)\right)^{\mathbf{T}} \mathbf{R}^{-\mathbf{1}}\left(\mathbf{y}-\mathbf{F}\left(\mathbf{x}_{k}\right)\right)\right)
$$

where $\mathbf{A}$ is the Hessian matrix, which is the second derivative of the cost function

$$
\mathbf{A}=\mathbf{F}^{\prime}\left(\mathbf{x}_{k}\right)^{\mathbf{T}} \mathbf{R}^{-1} \mathbf{F}^{\prime}\left(\mathbf{x}_{k}\right)-\mathbf{F}^{\prime \prime}\left(\mathbf{x}_{k}\right)^{\mathbf{T}} \mathbf{R}^{-\mathbf{1}}[\mathbf{y}-\mathbf{F}(\mathbf{x})] .
$$

The second term on the r.h.s. of $\mathbf{A}$ contains the second derivative of the forward model, $\mathbf{F}^{\prime \prime}(\mathbf{x})$. This term is small in the moderately non-linear case and becomes smaller with successive iterations, and so can be neglected (Rodgers, 2000, p. 85). The iterative process is repeated until the solution converges satisfactorily.

\subsection{The error estimate in the posterior}

The best estimate of the state vector, $\hat{\mathbf{x}}$, has the maximum probability $P(\hat{\mathbf{x}})$. An estimate of the error in $\hat{\mathbf{x}}$ is the variance of the probability distribution, $\sigma^{2}$. To find this variance, we first write the posterior distribution as a Gaussian function

$$
-2 \ln P(\mathbf{x} \mid \mathbf{y})=(\mathbf{x}-\hat{\mathbf{x}})^{\mathbf{T}} \hat{\mathbf{S}}^{-\mathbf{1}}(\mathbf{x}-\hat{\mathbf{x}})+c_{\mathbf{0}},
$$

where $\hat{\mathbf{S}}$ is a covariance matrix that contains the variance of the distribution and $c_{0}$ is a component of the Gaussian distribution that correctly normalizes the probability distribution. By equating like terms from Eq. 2 and Eq. 6, which are quadratic in $\mathrm{x}$, we can show that (Rodgers, 2000, p. 25)

$$
\hat{\mathbf{S}}^{-1}=\mathbf{F}(\mathbf{x})^{\mathbf{T}} \mathbf{R}^{-1} \mathbf{F}(\mathbf{x})+\mathbf{B}^{-1}
$$

where $\mathbf{B}^{-\mathbf{1}}$ is the associated posterior covariance matrix. This function is the same as the Hessian matrix (A) without the second derivative term, as defined in Eq. 5 , which is useful as the error estimate in $\hat{\mathbf{x}}$ has therefore already been calculated as part of the iteration method. 


\subsection{The forward models}

For a CBL, the simplest forward model relates observations of vertical velocity variance, $\sigma_{w}^{2}$, to the convective velocity $w_{*}$, which represent $\mathbf{y}$ and $\mathbf{x}$ respectively. We consider here two different examples of such mixed-layer scaling, the first of which was developed by Lenschow et al. (1980)

$$
\frac{\sigma_{w}^{2}}{w_{*}^{2}}=c_{1}\left(z / z_{i}\right)^{2 / 3}\left(1-c_{2} z / z_{i}\right)^{2}
$$

where $c_{1}$ and $c_{2}$ are empirically derived co-efficients. Lenschow et al. (1980) found that this relationship fitted well to measurements from the Minnesota experiment (Kaimal et al. (1976)), as well as the numerical model results of Deardorff (1970), and it has since been used extensively to verify observation datasets (e.g. Young 1988; Roth 2000; Chai and Lin 2004; Hogan et al. 2008).

Sorbjan (1988) proposed a function that was decomposed into a non-penetrative part (which describes the free convective processes taking place from the ground upwards) and a residual part (which describes the difference between the nonpenetrative, free convection and the penetrative convection that accounts for entrainment). The two components are then combined to give

$$
\frac{\sigma_{w}^{2}}{w_{*}^{2}}=c_{b}\left(z / z_{i}\right)^{2 / 3}\left(1-z / z_{i}\right)^{2 / 3}+c_{t} R^{2 / 3}\left(1-z / z_{i}+D\right)^{2 / 3}\left(z / z_{i}\right)^{2 / 3}
$$

where $c_{b}$ and $c_{t}$ are constants, $R$ is the ratio of the temperature fluxes at the top and bottom of the layer and $D=\Delta / z_{i}$ is the ratio of the depth of the entrainment zone, $\Delta$, to the depth of the mixed layer. In Sorbjan (1990), $c_{b}=1.1$ was found using tank experiments.

Preliminary experiments showed that when using Eq. 9 as a forward model, the optimal inverse method would only work sporadically. This is probably due to the function being too non-linear, meaning that the cost function was too difficult to solve using a Gauss-Newton iteration. As such, the second term in Eq. 9 was neglected, i.e. representing only non-penetrative convection.

Excluding the penetrative part of the function implies that entrainment processes are not considered, and hence the negative entrainment flux at the top of the boundary layer is not included in this forward model. Consideration of the penetrative part of the Sorbjan function shows that $w_{*}^{2}$, and therefore the heat flux, is inversely proportional to the magnitude of the dimensionless vertical velocity variance. Inclusion of the penetrative part of the Sorbjan function would therefore result in lower values of the estimated heat flux.

More generally, consideration of both forward model functions shows that the surface heat flux is proportional to $\sigma_{w}^{3}$, and is inversely proportional to the boundary-layer height. This suggests that the estimated heat flux will be more sensitive to errors in the measured $\sigma_{w}^{2}$ than to errors in $z_{i}$. In our implementation we have not chosen to incoporate $z_{i}$ observations. 


\begin{tabular}{ll}
\hline Wavelength & $1.55 \mu \mathrm{m}$ \\
Pulse Repetition Frequency & $15 \mathrm{kHz}$ \\
Focus & $\infty$ \\
Integration time & $32 \mathrm{sec}$ \\
Resolution & $36 \mathrm{~m}$
\end{tabular}

Table 1 Specifications of the Doppler lidar operation

\section{Characterizing errors in the observations}

The Doppler lidar used in this work, which was developed by Halo Photonics, is a coherent, heterodyne system. Specifications of the lidar operation are shown in Table 1, and a full description of an identical instrument constructed by Halo Photonics and its performance is given in Pearson et al. (2009). The measurement integration time of the lidar is $32 \mathrm{sec}$, which is insufficient to capture the smallest scales of turbulence, and so a technique is used to estimate the un-sampled vertical velocity variance in which the inertial sub-range of the velocity measurements is extrapolated at the highest frequencies (e.g. Bouniol et al. (2004) and Hogan et al. (2008)).

\subsection{Assessing the errors in wind-velocity measurements}

Pearson et al. (2009) and O'Connor et al. (2010) describe how the theoretical performance of the Doppler velocity estimation can be calculated. The dimensionless value $\alpha$ characterizes the ratio of the photon count to the speckle count as shown by O'Connor et al. (2010):

$$
\alpha=S N R /\left[(2 \pi)^{1 / 2}(\Delta v / B)\right],
$$

where $S N R$ is the wideband signal-to-noise ratio, $\Delta v$ is the signal spectral width (i.e. the bandwidth of the emitted laser beam) and $B$ is the bandwidth of the receiver. For this instrument, $\Delta v \approx 1.5 \mathrm{~m} \mathrm{~s}^{-1}$ (Pearson et al., 2009). The theoretical standard deviation of a Doppler velocity estimate for a weak signal regime, $\epsilon_{w}$, is given by Rye and Hardesty (1993), who showed it to be:

$$
\epsilon_{w}=\left(\frac{\Delta v^{2} \sqrt{2}}{\alpha N_{p}}\left(1+1.6 \alpha+0.4 \alpha^{2}\right)\right)^{1 / 2},
$$

where $N_{p}$ is the accumulated photon count by the detector. This is calculated as

$$
N_{p}=(S N R) M n
$$

in which $M$ is the number of data points per range gate and $n$ is the number of pulses averaged to make the velocity estimate.

The error in the Doppler velocity measurement is used to calculate the instrumental error in a measurement of the vertical velocity variance. This error is 
calculated using the method of Gal-Chen and Xu (1992). We define the standard deviation of the error in the variance, $\sigma\left(\epsilon_{\sigma_{w}^{2}}\right)$, as

$$
\sigma\left(\epsilon_{\sigma_{w}^{2}}\right)=2 \sigma_{w} \sigma\left(\epsilon_{w}\right),
$$

where $\sigma_{w}$ is the standard deviation of the Doppler velocity estimates and $\sigma\left(\epsilon_{w}\right)$ is the standard deviation of the errors in the Doppler velocity measurements as calculated in Eq. 11. For $N$ measurements, the error is

$$
\sigma\left(\epsilon_{\sigma_{w}^{2}}\right)=\left(2 / N^{1 / 2}\right) \sigma_{w} \sigma\left(\epsilon_{w}\right)
$$

\subsection{The sampling error}

Lenschow et al. (1994) derive a sampling error for a time-averaged turbulent statistic that comprises of two parts; a systematic error that arises due to the difference between the ensemble variance, $\left\langle\sigma_{w}^{2}\right\rangle$, and the mean of a set of time-averaged variances, $\overline{\sigma_{w}^{2}(T)}$, where $T$ is the sampling time of the measurement; and a random error that represents the scatter of the time-averaged variances about the ensemble-averaged variance, calculated as the variance of the time-averaged variances, $\sigma_{\text {var }}^{2}(T)$. Many studies neglect the systematic part of the sampling error (e.g. Angevine et al. 1994; Drennan et al. 2007) as it can be significantly smaller than the random error, particularly for larger sampling times. Here, we shall include the systematic error as part of our formulation.

Functions for the systematic and random errors were derived by Lenschow et al. (1994), and for the vertical velocity variance the absolute errors can be written as:

$$
\begin{aligned}
\epsilon_{\text {sys }} & =\left(1-\left(1-a_{s}\left(\frac{\tau_{w}}{T}\right)\right)\right) \sigma_{w}^{2}(T), \\
\epsilon_{\text {rand }} & =\left(a_{r}\left(\frac{\tau_{w}}{T}\right)^{1 / 2}\right) \sigma_{w}^{2}(T),
\end{aligned}
$$

where $a_{r}$ and $a_{s}$ are constants relating to the skewness (or Gaussianity) of the vertical velocity measurements, and $\tau_{w}$ is the integral time scale. In the CBL, $w(t)$ is a positively skewed process, but for practical purposes the assumption is made that $w(t)$ is Gaussian, making $a_{r}$ and $a_{s}$ both equal to 2. Lenschow et al. (1994) showed that these functions are good approximations within the limit $T \gg \tau_{w}$; as a rule of thumb this is typically $\tau_{w} \geq 10$. Equations 15 and 16 are combined to give an equation for the sampling error

$$
\epsilon_{\mathrm{samp}}=\sqrt{\epsilon_{\mathrm{sys}}^{2}+\epsilon_{\mathrm{rand}}^{2}}
$$

In our study, the integral time scale is calculated for each averaging period as the integral of the autocorrelation function of the vertical velocity. Typically, $\tau_{w}$ is of the order of $100 \mathrm{sec}$, which is similar to values of $\tau_{w}$ found by Lenschow and Wulfmeyer (2000). As a 60-min averaging period is used, this gives $\sim T / \tau_{w} \geq 30$. 


\section{Validation of optimal estimation method using Large-Eddy Simulation (LES) data}

LES data simulating the CBL under different wind-shear conditions are used to validate the optimal inverse method, as well as provide insight into both the sampling error and the error due to the assumptions in the forward models. The measurements of individual profiles by the Doppler lidar are simulated and compared with domain-averaged statistics; these are assumed to be equivalent to ensembleaveraged statistics.

\subsection{Description of the Large-Eddy Model (LEM)}

The model used was the UK Met Office Large Eddy Model (LEM) (Shutts and Gray, 1994). Simulations were performed with increasing values of the geostrophic wind $\left(\mathrm{u}_{g}=2,5\right.$ and $\left.10 \mathrm{~m} \mathrm{~s}^{-1}\right)$, referred to as runs 1,2 and 3 respectively. The geostrophic wind is determined above the boundary-layer top where the horizontal windspeed becomes constant with height. The three runs have values of $w_{*} / u_{*}=$ 10.0, 6.3 and 4.5 respectively. The model domain was divided into $100^{3}$ gridpoints, with a horizontal resolution of $100 \mathrm{~m}$, and a vertical resolution of $30 \mathrm{~m}$ (similar to the gate length of the Doppler lidar). The model timestep was $4 \mathrm{sec}$ (this is smaller than that of the Doppler lidar instrument used, although this does not affect our conclusions). Domain-averaged statistics were provided at each height every $30 \mathrm{~min}$ and include subgrid-scale turbulence. The LEM requires a spin-up time of about 1.5 hours to reach an equilibrium state, and so data in the first hour are not included in the analysis.

In order to validate the optimal inverse method, three profiles of vertical wind velocity were extracted from the model domain in a line perpendicular to the flow to simulate "virtual lidar" profiles. If we assume a typical time scale for the flow of $100 \mathrm{sec}$, and a horizontal wind speed of $7.5 \mathrm{~m} \mathrm{~s}^{-1}$ (as seen in the mixed layer in run 3), then the decorrelation length-scale for the flow is about $750 \mathrm{~m}$. As the profiles are separated by 25 grid points, or $2500 \mathrm{~m}$, then they can be considered to be statistically independent.

\subsection{Comparison of LEM vertical velocity variance profiles with results from} previous studies

Figure 1 shows the LEM normalized vertical velocity variance profiles compared with previous datasets. These include: the aircraft and tank data that Lenschow et al. (1980) and Sorbjan (1990) used to derive the forward model variance functions, along with the functions themselves; data from three LES runs with increasing model resolution $\left(32^{3}, 64^{3}\right.$ and $256^{3}$ gridpoints) from Sullivan and Patton (2011); and measurements from the NOAA High Resolution Doppler Lidar (HRDL) from Lenschow et al. (2012).

The LEM profile is compared with the LES data of Sullivan and Patton (2011) to assess whether grid resolution limits the computed variance. They found that the higher-order statistics converge and become grid-independent when the resolution ratio $z_{i} /\left(C_{s} \Delta f\right)>310$, where $z_{i}$ is the mixed-layer height, $C_{s}$ is the Smagorinsky 
constant, and $\Delta f$ is the filter cut-off scale. By considering a typical range of mixed-layer heights in the LEM simulations, from 800 to $1300 \mathrm{~m}$, we find a range in resolution ratio from $z_{i} /\left(C_{s} \Delta f\right)=92-149$. Thus, according to the criterion set by Sullivan and Patton (2011), the statistics from the LEM simulations cannot be said to have fully converged, and so the statistics will be grid-dependent. However, the LEM profile is seen to agree best with the most highly resolved run with $256^{3}$ gridpoints, suggesting that the limited resolution is not significantly affecting the magnitude of the variance profiles.

The LEM profile lies within the scatter of most of the data-sets, suggesting that it is in good agreement with them. However, the Limagne aircraft data-set is notably higher than all of the other data, and perhaps should be treated with caution. The agreement between the LEM data and the Lenschow function is also very good. The peak in the Sorbjan function sits higher at $z / z_{i}=0.5$, which is to be expected as it represents only non-penetrative convection. This gives confidence that the LEM data-set is suitable for testing the optimal estimation method with both convective boundary layer forward models.

\subsection{Testing of the optimal inverse method}

Figure 2 shows an example of the two forward models fitted to 60-min averaged variance profiles extracted from the middle of the domain of run 1 . The profiles of variance are quite irregular, in particular the profile for hour 4-5 has two distinct peaks and a minimum mid-boundary layer. The sampling error in the variance profile, calculated using Eq. 17, varies between 25-35\%. The Lenschow forward model fits the variance profiles well, in particular at the top and the bottom of the mixed layer where the small sampling error constrains the fit. The Sorbjan forward model does not fit the data as well, in particular due to the height of the maximum variance in the LEM data being lower than $0.5 z / z_{i}$. However, the magnitude of the maximum variance of the Sorbjan forward model is similar to that of the Lenschow forward model.

The estimated values of $\mathrm{Q}_{H}$ for all runs and profile locations for both forward models are shown in Fig. 3 and statistics are shown in Table 2. The results from both forward models are very well correlated, as both forward models estimate similar values for the maximum variance. The estimated heat fluxes compare well with the heat flux input into the LEM $\left(179.4 \mathrm{~W} \mathrm{~m}^{-2}\right)$, with most points agreeing within one standard deviation (calculated from the covariance matrix of the posterior as described in Sect. 2.3). However, some points do not lie within one standard deviation of the input heat flux; this spread in the results may be partially due to model error (i.e. the error in the fitted coefficients of the forward models), but also due to the fact that turbulent processes are inherently stochastic, as evidenced by the double peak variance distribution for hour 4-5 that lies outside the sampling errors.

The average heat flux over all three runs and for all three points is $164 \mathrm{~W}$ $\mathrm{m}^{-2}\left(\sigma=10.2 \mathrm{~W} \mathrm{~m}^{-2}\right)$ for the Lenschow forward model, and $180 \mathrm{~W} \mathrm{~m}^{-2}(\sigma=$ $6.8 \mathrm{~W} \mathrm{~m}^{-2}$ ) for the Sorbjan model. The overall underestimate of the Lenschow model is due to the small negative bias in the flux estimates with increasing shear. This may be due to the lack of explicit dependence on $u_{*}$ in the forward model scaling. The Sorbjan model overall produces flux estimates with a greater spread, 


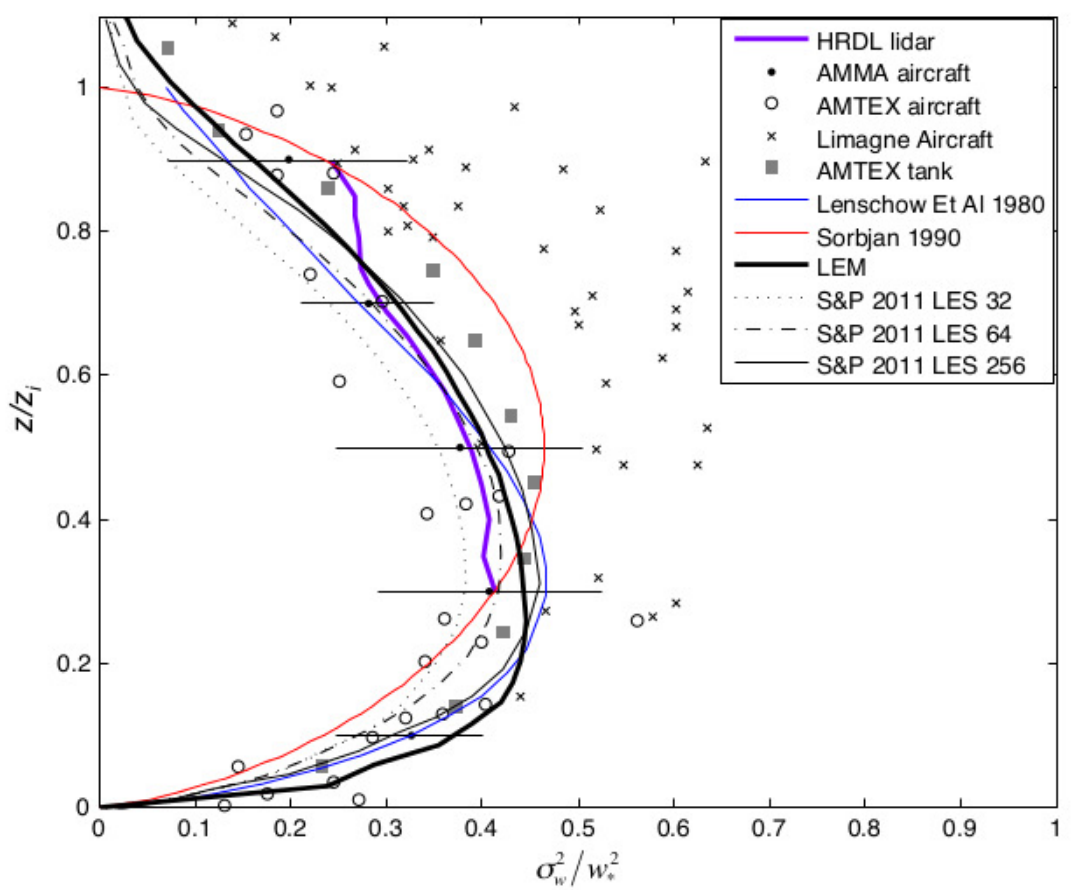

Fig. 1 Normalized vertical velocity variance measurements from NOAA's High Resolution Doppler Lidar (HRDL) (thick purple line) and African Monsoon Multidisciplinary Analysis (AMMA) aircraft campaign (black dots with one standard deviation error bars), both taken from Lenschow et al. (2012); measurements from the Air Mass Transformation Experiment (AMTEX) campaign (empty circles) and Limagne (crosses) aircraft campaigns, and tank data also from the AMTEX campaign (grey squares), all taken from Sorbjan (1991); the normalized, domain-averaged vertical velocity variance from the LEM (thick black line); the Lenschow (thin blue line) and Sorbjan (thin red line) variance functions; and normalized, domain-averaged profiles of vertical velocity variance for LES runs with resolutions of $32^{3}, 64^{3}$ and $256^{3}$ from Sullivan and Patton (2011) (dotted, dash-dotted and solid thin grey lines respectively).

perhaps reflecting its poorer fit, but shows no significant trend with increasing shear. For both models the error in the flux estimates, and spread of the estimates themselves, reduce with increasing shear due to the reduction in $\tau_{w}$ with less convective conditions. Overall, the forward models give reasonable estimates for a CBL with increasing shear, thus justifying a simpler formulation based on purely mixed-layer scaling when combined with the optimal inverse method.

In conclusion, the optimal inverse method has worked well in retrieving heat fluxes in agreement with the heat flux input into the LEM. The estimated uncertainty in the heat fluxes captures most of the variability around the true value. The forward models themselves are relatively robust under increasing shear, the small negative bias in the Lenschow model results at this stage would not justify the addition of $u_{*}$ to the model. This gives confidence in retaining the model formulation when applying this method to data measured in a real CBL, where $w_{*} / u_{*}$ varies. 

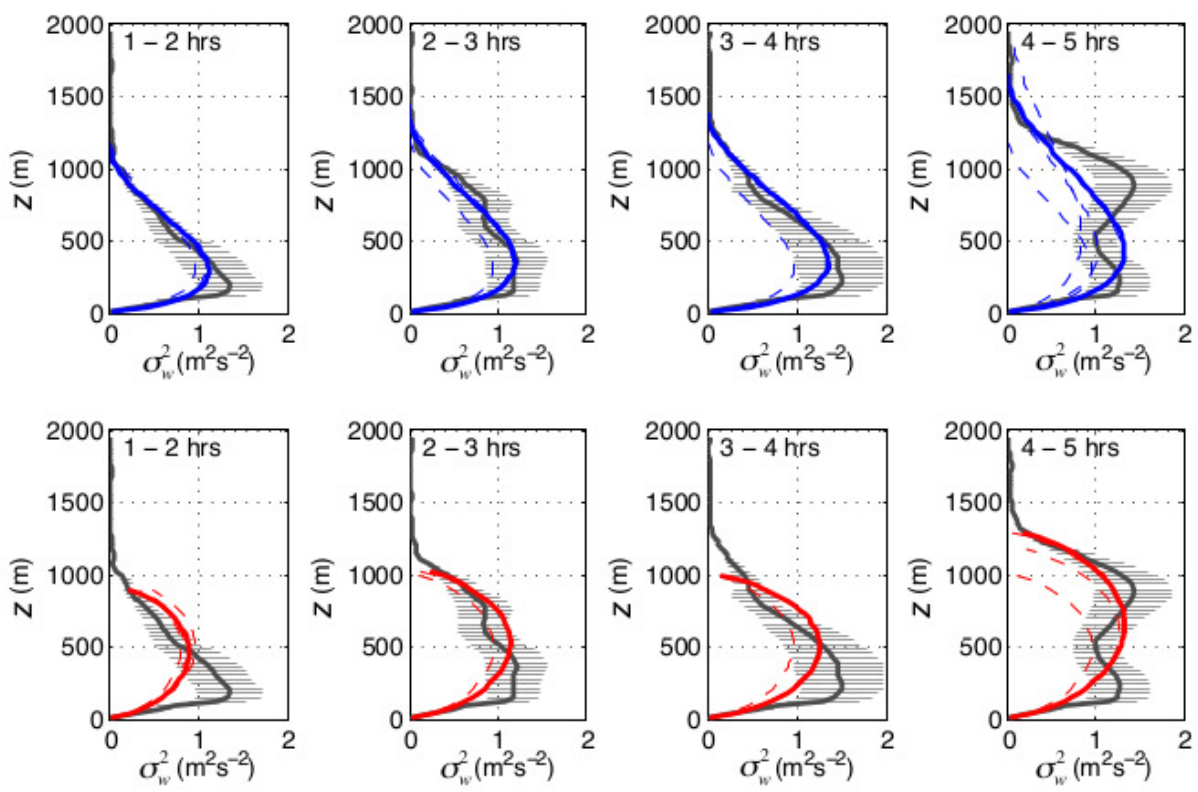

Fig. 2 60-min averaged profiles of the vertical velocity variance (thick grey line) from the point number 2 of the LEM domain, for run 1. The sampling error associated with the profile of variance, calculated using Eq. 17, is shown by the thin horizontal black lines. The plots along the top row show the Lenschow forward model after fitting to the variance (thick blue line) as well as the previous iterations (dashed blue lines). Similarly, the bottom row shows the Sorbjan model fitted to the variance (thick red line) as well as the previous iterations (dashed red lines).

\section{Estimating heat fluxes from full-scale data}

The method is now tested using Doppler lidar data from the Chilbolton Observatory, UK. Estimated heat fluxes are compared with those from a sonic anemometer at the site.

\subsection{Description of experimental site}

The Chilbolton Facility for Atmospheric and Radio Research (CFARR), is located in the county of Hampshire, UK $\left(51.14500^{\circ} \mathrm{N} 1.43667^{\circ} \mathrm{W}\right)$. As can be seen in Fig.

\begin{tabular}{|c|c|c|c|c|c|c|}
\hline \multirow[b]{2}{*}{ Run } & \multicolumn{3}{|c|}{ Lenschow } & \multicolumn{3}{|c|}{ Sorbjan } \\
\hline & 1 & 2 & 3 & 1 & 2 & 3 \\
\hline$\overline{\mathrm{Q}_{H}}\left(\mathrm{Wm}^{-2}\right)$ & 184.2 & 162.4 & 142.4 & 213.0 & 177.2 & 157.2 \\
\hline$\delta\left(\mathrm{Q}_{H}\right)$ & 0.19 & 0.15 & 0.17 & 0.23 & 0.13 & 0.16 \\
\hline$\overline{\sigma\left(\mathrm{Q}_{H}\right)}\left(\mathrm{Wm}^{-2}\right)$ & 30.0 & 24.5 & 20.3 & 32.0 & 24.4 & 20.1 \\
\hline
\end{tabular}

Table 2 The mean estimated heat flux, relative error and mean standard deviation for the three runs with each forward model. 

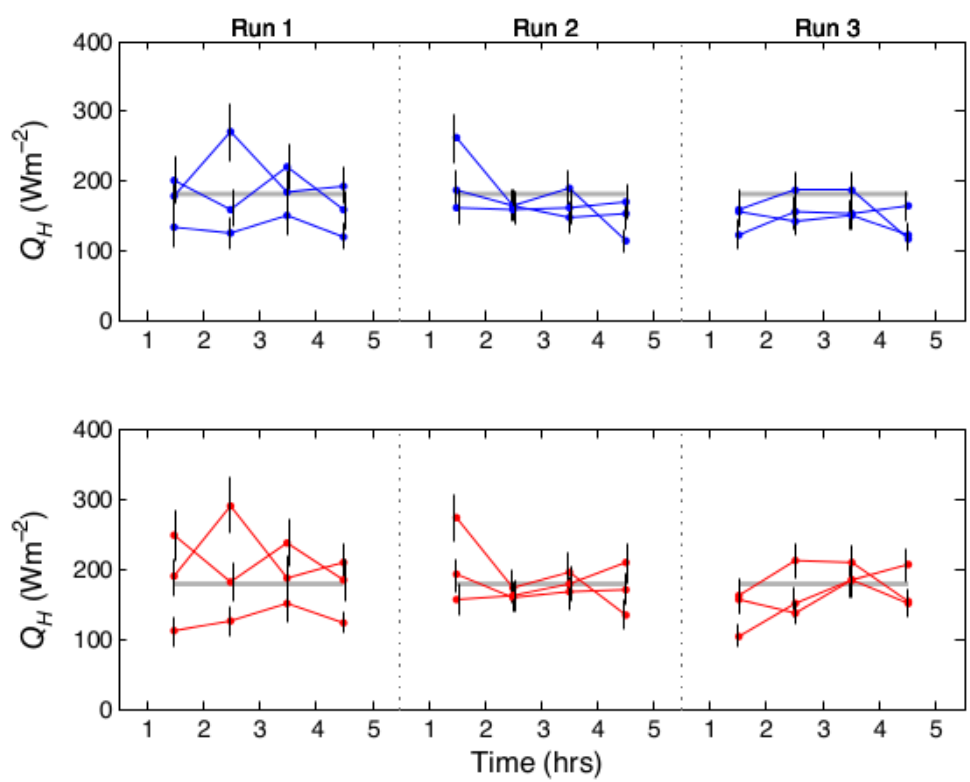

Fig. 3 The surface sensible heat fluxes estimated using the inverse method with the profiles of simulated lidar measurements from the LEM. Results when using the Lenschow forward model are shown in blue, results when using the Sorbjan forward model are shown in red. The results for all three independent profiles are plotted on top of the heat flux prescribed in the LEM (thick grey line), with vertical error bars indicating one standard deviation as calculated using the inverse method.

4, the area surrounding the observatory is predominantly rural with two potential sources of significant inhomogeneity: Chilbolton village, which is situated roughly $700 \mathrm{~m}$ to the north, and a wooded area approximately $1 \mathrm{~km}$ to the west alongside the banks of the river Test. The lidar is mounted at approximately $1.5 \mathrm{~m}$ on the wall of the main building. The sonic anemometer is mounted at a height of $5 \mathrm{~m}$, approximately $200 \mathrm{~m}$ away on the 'range', which is $400 \mathrm{~m}$ in length with grass of about $30-40 \mathrm{~mm}$ in length.

As the forward models used are based upon mixed-layer similarity scaling, there are some criteria that must be met by the data in order that they are suitable for use. The boundary layer must be convectively driven, with little or no shear production of turbulence, and cloud cover should also be negligible so that turbulence is mainly driven by the surface fluxes. Plots of vertical velocity and backscatter were examined by eye between the months of May to September 2008 in order to select days with very little or no cloud cover visible in the backscatter, and when the vertical velocity shows a deep well-mixed layer during the daytime. Unfortunately technical problems with the sonic anemometer during this time period limited the number of days available for analysis. Thirteen days were found in total: the $6,7,8,11$ and 12 May, the 7, 8, 9, 17 and 19 June, the 30 July, and the 26 and 28 September. Measurement data between the hours of 0900 and 1700 


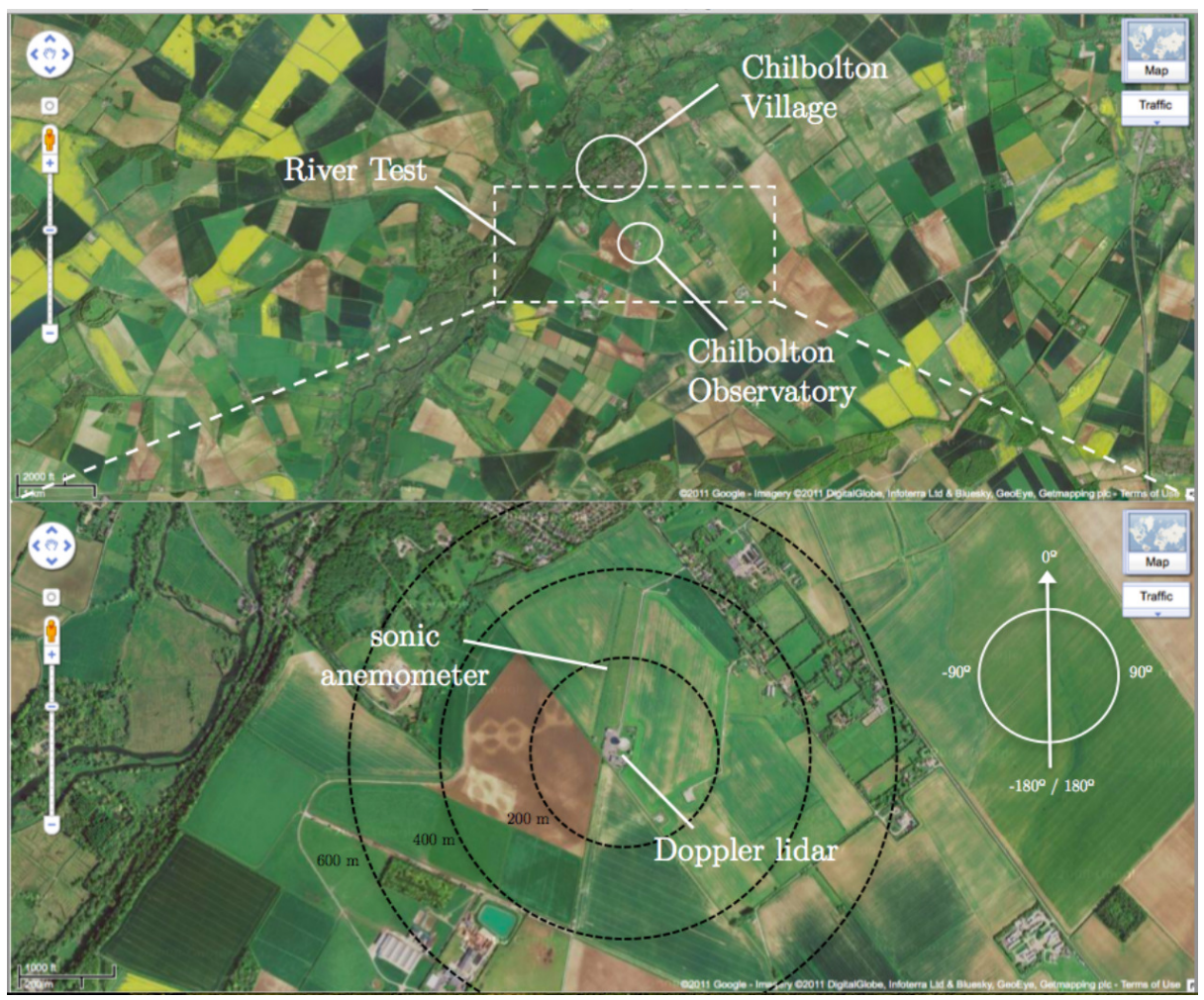

Fig. 4 The upper part of the figure shows a satellite image of the area surrounding the Chilbolton Observatory. Chilbolton Village is circled to the north of the Observatory site, and the River Test, which is surrounded by woodland, is labelled to the west. The lower part shows a magnified image of the observatory site as indicated by the dashed white rectangle. The locations of the Doppler lidar and the sonic anemometer are indicated; the concentric rings show distances in steps of $200 \mathrm{~m}$ centred upon the lidar location. (C) Google Imagery, 2011

UTC were examined for these days; during these times values of $w_{*} / u_{*}$ ranged between 1.8 and 8.9, with an average value of 3.6.

\subsection{Profile fits for a typical day}

Figure 5 shows the forward models fitted to the variance profiles on 7 May 2008. The diurnal evolution of the CBL is evident, with maximum variance and deepest mixed layer occurring in the middle of the day. It can be seen that for different time periods one forward model is generally better suited than the other i.e. the Sorbjan function is a better fit than the Lenschow function for 1300-1400. The optimal inverse method was occasionally unable to fit the Lenschow function to profiles in which the measured variance profile lacks a defined peak e.g. from 09001000 , which resembles a neutral profile. Overall, the Sorbjan function proved more robust, possibly due to its symmetrical shape, and could be fitted to most profiles. 

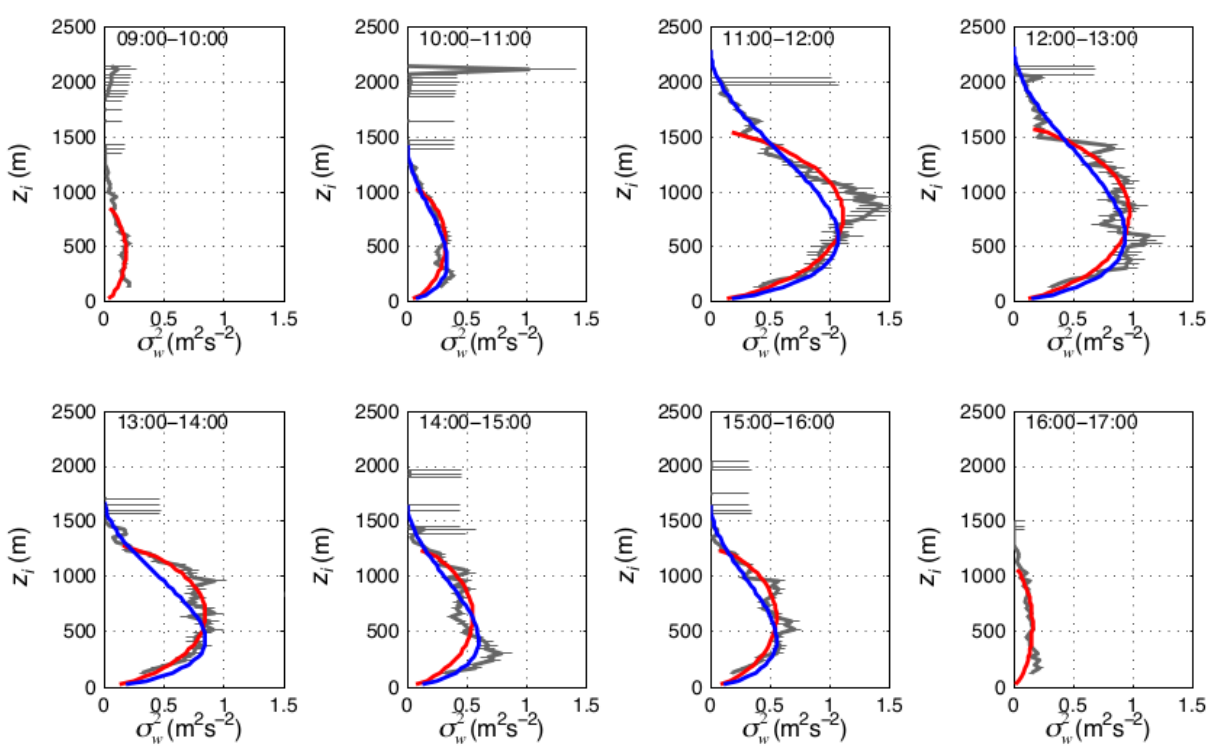

Fig. 5 Hourly plots of the measured vertical velocity variance profile measured by the lidar (thick grey line) on the 7 May, 2008 (all times are in UTC). Errors are indicated by the horizontal grey lines. The Lenschow function is indicated by the blue line, and the Sorbjan function by the red line.

\subsection{Heat flux estimation for all days}

Figures 6 and 7 show time series of heat fluxes estimated by the optimal inverse method for all days compared to those measured using the sonic anemometer. A clear diurnal cycle can be seen with generally good agreement with the sonic anemometer fluxes. A negative bias for both forward models can be seen in the mornings: this occurred when the variance profile was more neutral in shape (i.e. monotonically decreasing) as shown in Fig. 5. Occasionally, mid-day fluxes are extremely large, and inconsistent with periods before and after. These were due to large spikes in variance observed by the lidar in the middle of the boundary layer, rather than smooth peaks, to which the models were fitted. These estimates therefore seem unphysically large and are treated as outliers.

The methodology of Willmott et al. (1985) is used to calculate the systematic and non-systematic root-mean-square errors $\left(R M S E_{\text {sys }}\right.$ and $R M S E_{n o n s y s}$ respectively) for the afternoon results. $R M S E_{s y s}$ describes the linear bias (a measure of the underestimation), while $R M S E_{n o n s y s}$ can be interpreted as the random error (a measure of the variability) in the results. $R M S E_{s y s}$ is larger for the heat fluxes estimated using the Lenschow function $\left(-71 \mathrm{~W} \mathrm{~m}^{-2}\right)$ than those using the Sorbjan function $\left(-55 \mathrm{~W} \mathrm{~m}^{-2}\right)$, indicating a larger bias when using the Lenschow function. $R M S E_{n o n s y s}$ is the same for the heat fluxes estimated using both forward models $\left(23 \mathrm{~W} \mathrm{~m}^{-2}\right)$, indicating that they both have a similar scatter in the results. This analysis shows that the linear bias in the results constitutes the majority of the error for this method. 

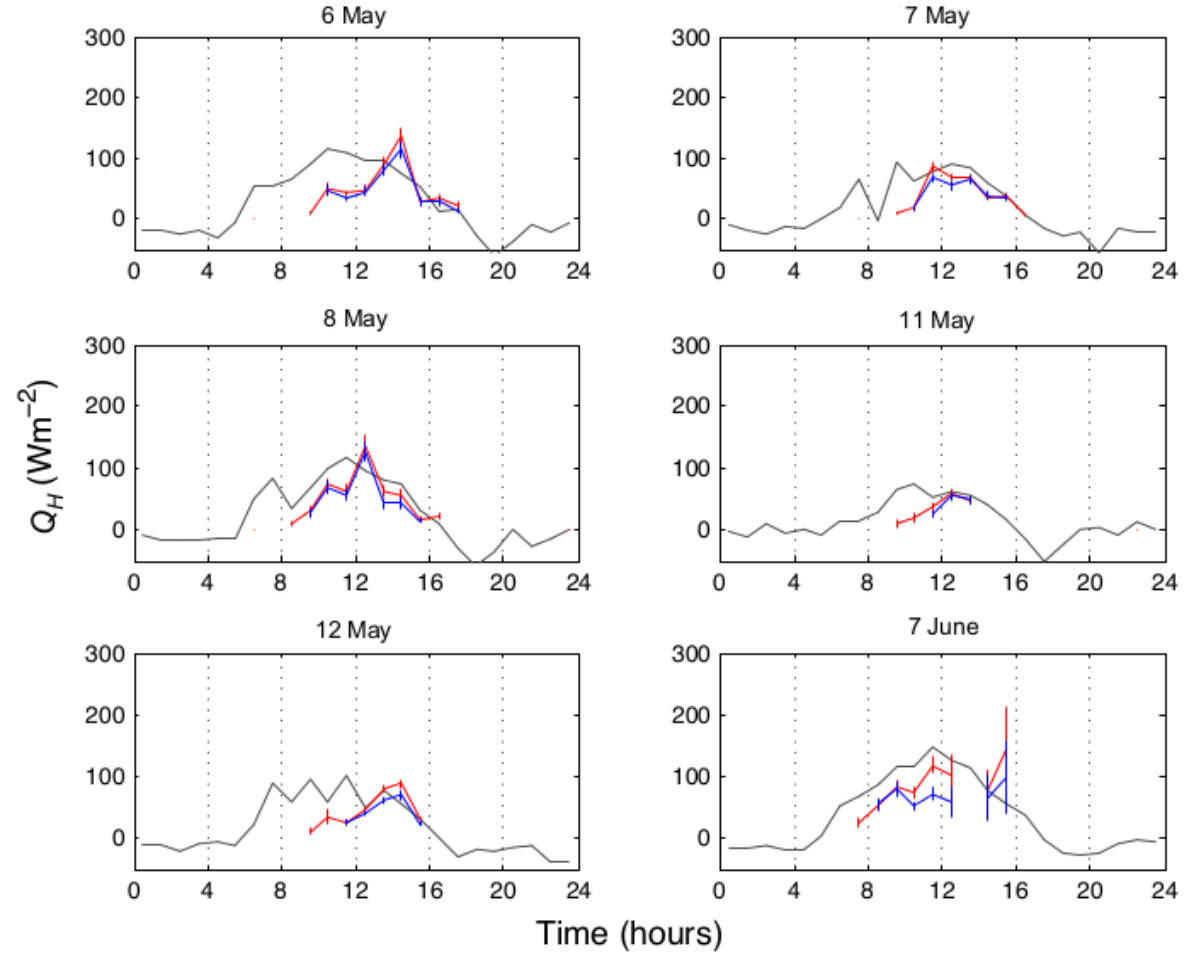

Fig. 6 Time series comparing the lidar estimated surface sensible heat flux for the two variance profile models (Lenschow model - blue line, Sorbjan model - red line) to that measured by the sonic anemometer (grey line). The vertical lines show errors in estimates of the heat flux; for the optimal estimation method it is the variance in the state vector, for the sonic anemometer it is the sampling error (NB: the error for the sonic anemometer fluxes is approx. $1 \%$ and thus not visible on graph.)

The relative errors in the surface sensible heat fluxes estimated by the optimal inverse method have a median value of $17 \%$ when using the Sorbjan function, and $18 \%$ when using the Lenschow function. Comparing with previous results, Angevine et al. (1994) estimated a relative uncertainty of $30 \%$ in their results, although their analysis only takes into account a parametrized sampling error in the vertical velocity variance measurement. The only error considered in the sonic anemometer measurements of the heat flux is the sampling error, which is very small for these results, with the median relative error less than $1 \%$. This is due to the relatively short integral time scales measured by the sonic anemometer, which are of the order of $1 \mathrm{~s}$, compared to the integral time scales measured by the lidar, which are of the order of $100 \mathrm{sec}$. The shorter integral timescale is a result of the height of the sonic anemometer: the proximity of the instrument to the ground limits the size of the turbulent eddies that it is measuring. 

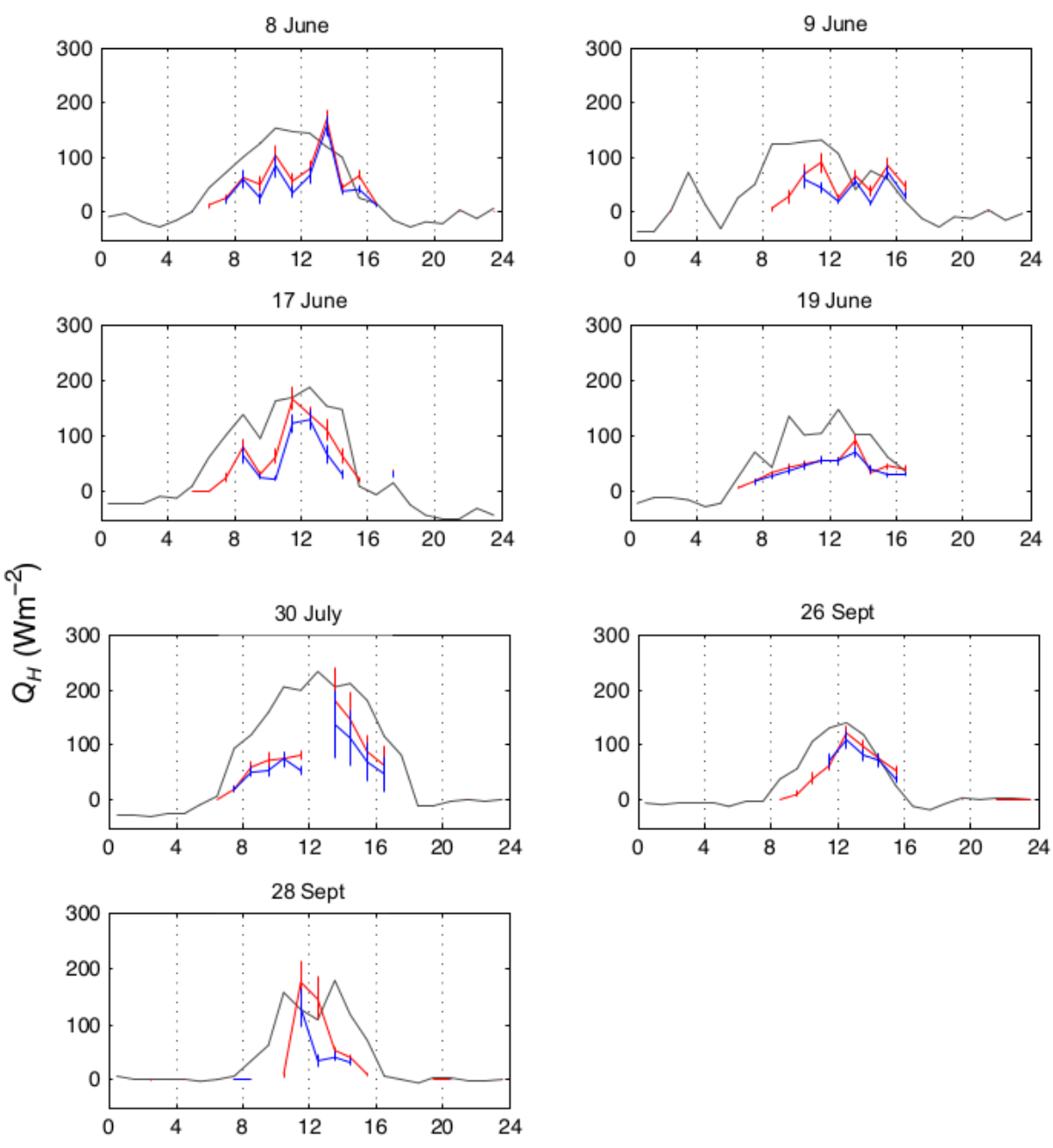

\section{Time (hours)}

Fig. 7 As for Fig. 6.

5.4 Exploring the scatter and bias in the results

There are several possible explanations for the bias between the heat fluxes estimated using the optimal inverse method and those measured by the sonic anemometer that are now explored.

1) Due to the limited sampling rate, the lidar may still underestimate the vertical velocity variance, and thus the heat flux, despite the use of the inertial sub-range extrapolation technique (as mentioned in Sect. 3). This is unlikely as the measurements are made in the daytime, when the underestimation of the variance 

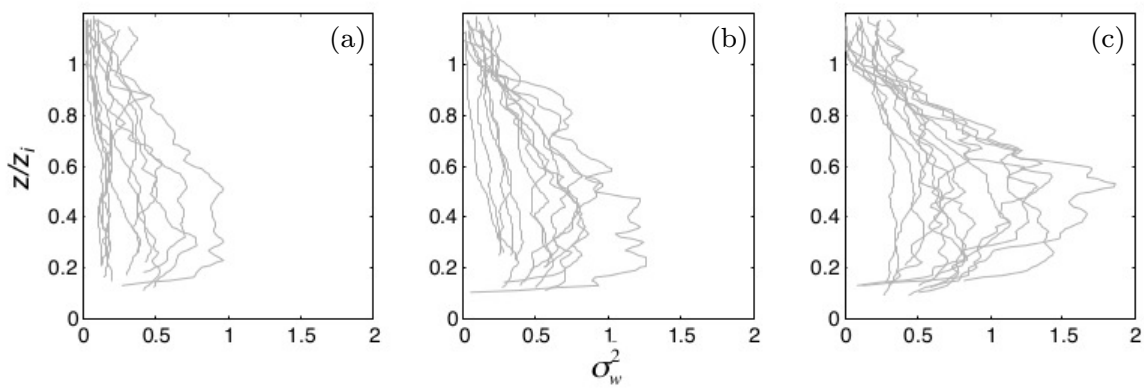

Fig. 8 (a) Profiles of variance measured by the lidar between 0900 and 1000 . Profiles from individual days are shown by the thin grey lines. (b) Profiles measured between 1000 and 1100 . (c) Profiles measured between 1100 and 1200 .

by the lidar is minimized due to the large size of the turbulent eddies. However, underestimation due to spatial averaging over each $30 \mathrm{~m}$ range gate has not been explored.

2) The optimal inverse method may be overestimating the mixing height, which is part of the predicted state vector, and thus underestimating the heat flux due to the inverse relationship between $z_{i}$ and $Q_{H}$. The estimated mixing heights using both forward models $\left(z_{i S}\right.$ for the Sorbjan function and $z_{i L}$ for the Lenschow function) were compared with heights calculated using the vertical velocity variance threshold method described in Barlow et al. (2011). This method involves defining a ground-based turbulent layer of depth $z_{i V}$ in which $\sigma_{w}^{2}>0.1 \mathrm{~m}^{2} \mathrm{~s}^{-2}$ at all heights. On average, the mixing height estimated using the Lenschow forward model is $215 \mathrm{~m}$ higher than that estimated using the Sorbjan forward model, which is consistent with the Lenschow function producing negatively biased heat fluxes. However, $z_{i L}$ is closer to $z_{i V}: z_{i L}$ is on average only $37 \mathrm{~m}$ lower than $z_{i V}$, whilst $z_{i S}$ is $252 \mathrm{~m}$ lower than $z_{i V}$. This suggests that the optimal inverse estimate of mixing height using the Lenschow function is not overestimated, and therefore does not explain the underestimation of heat fluxes.

3) Differences in the source areas of the two instruments may be causing a bias between the heat fluxes. Approximately $200 \mathrm{~m}$ to the south of the sonic anemometer are some buildings which may be drier and warmer than the surrounding vegetation. If they lie within the source area of the sonic anemometer, which is smaller than for the lidar due to the lower measurement height, the measured heat flux may be larger than that calculated using the lidar measurements. The heat fluxes measured using the sonic anemometer showed no significant relationship with wind direction, i.e. were not anomalously large when the wind direction was aligned with the buildings. We conclude that differences in the source areas do not explain the negative bias in lidar-derived fluxes.

4) Fig. 8 shows the variance profiles measured by the lidar in the morning for each hour between 0900 and 1200. It is clear from plot a) that between 0900 and 1000 most of the variance profiles are monotonically decreasing. Between 1000 and 1100 , and 1100 and 1200 , most of the variance profiles are similar in shape to the forward models (i.e. they possess a peak in the middle of the boundary layer). 
Sonic anemometer measurements of $w_{*} / u_{*}$ in the morning ranged between 1.5 and 5.2 with an average value of 2.7 between 0900 and 1000 . These values suggest that the layer is convectively unstable whereas the measured profiles of variance were neutral in shape (i.e. monotonically decreasing). Beare (2008) studied the role of shear in the morning transitional layer using an LES, simulating a CBL growing within a stable layer. He showed that during the early stages of the growing CBL, the turbulent kinetic energy budget of the layer is still dominated by shear, giving a mixed "convective-stable" state of the boundary layer. The classic CBL state, dominated by buoyancy, is only reached after several hours of simulation, when the previous night's residual layer has been completely eroded by thermals. These results suggest that the chosen forward models may not appropriate for use in the early morning when boundary layer structure is more complex and shear may be playing a dominant role. Beare (2008) suggested scaling to account for this effect, which could form the basis of a more sophisticated forward model in future development of the present work.

\section{Conclusions}

We have presented a novel technique that uses an optimal inverse method with Doppler lidar measurements of turbulence to estimate the surface sensible heat flux. This is the first time such a method has been used for a small-scale boundarylayer application. The heat fluxes estimated using this method are assumed to have an effective source area of tens of $\mathrm{km}^{-} 2$, and thus the inverse method for estimating fluxes may be more appropriate over heterogeneous surfaces than traditional point measurement methods, such as those that use sonic anemometers, which have a smaller source area.

The simple case of a CBL with a homogeneous surface heat flux was chosen to test the optimal inverse method. Two forward models of mixed-layer scaling were chosen to relate vertical velocity variance to surface heat flux, namely Lenschow et al. (1980) and Sorbjan (1990). The error covariance matrix for the Doppler lidar observations of vertical velocity variance was derived as a combination of instrumental and sampling errors. The error in the estimated state vector (in this case the surface heat flux) was derived by assuming the posterior probability function to be Gaussian.

Firstly, the method was tested using an LES of a CBL with constant surface heat flux and three runs with increasing geostrophic wind speed. Three independent "virtual lidar" profiles were taken across the domain and used with the inverse method, the error based solely on sampling considerations. The optimal inverse method successfully fitted the forward models to the LES variance profiles, and the majority of the estimated heat fluxes agreed within error with the input heat flux. The estimated heat fluxes varied little with increasing wind speed, suggesting that the forward models in this case were relatively robust and did not require explicit inclusion of the effect of shear.

Secondly, the optimal inverse method was applied to Doppler lidar data from the Chilbolton Observatory, UK, which lies in relatively flat terrain with moderately heterogeneous land use. Estimated heat fluxes were compared with those from a sonic anemometer mounted at a height of $5 \mathrm{~m}$. The comparison showed that the optimal inverse estimates were linearly correlated with the point mea- 
surements with a degree of scatter $\left(23 \mathrm{~W} \mathrm{~m}^{-2}\right)$ and a significant negative bias: $-71 \mathrm{~W} \mathrm{~m}^{-2}$ for the Lenschow model and $-55 \mathrm{~W} \mathrm{~m}^{-2}$ for the Sorbjan model. As the bias was more pronounced in the morning, it was noted that variance profiles at that time tended to lack a peak, instead decreasing monotonically with height, despite a large surface heat flux. In these cases the forward models would be successfully fitted to the data, despite the profile being "shear-like" rather than "convective-like", resulting in a reduced heat-flux estimate. Extending the forward model to include surface-layer scaling (i.e. the friction velocity) might be a solution to this issue. The heterogeneity of the site, given the difference in source areas for the sonic anemometer and the lidar, was considered: a positive bias in sonic anemometer-derived heat fluxes could not be found with wind direction, suggesting that this did not explain the overall negative bias of the optimal estimates. However, this result suggested that the optimal estimate method should be tested against either path-averaged or area-averaged flux data, or flux data from a truly homogeneous site.

Overall, the optimal inverse method was shown to provide reasonable flux estimates for the simple case of a CBL. Discrepancies were shown to be largely related to the choice of forward model, which was kept deliberately simple for this study. Results shown here demonstrate that this method has great promise in utilizing ground-based remote sensing observations of the boundary layer to derive surface fluxes. Extension of the method is relatively straight-forward, and could include a more complex forward model, or even independent measurements as additional constraints (e.g. boundary-layer depth).

\section{Acknowledgements}

The authors wish to thank Alan Grant for running the LEM to provide convective boundary layer simulations, and guidance in interpretation of the results. T. Dunbar was funded through a Natural Environment Research Council grant reference number NE/F00706X/1.

\section{References}

Angevine WM, Doviak RJ, Sorbjan Z (1994) Remote sensing of vertical velocity variance and surface heat flux in a convective boundary layer. J Appl Meteorol 33:977-983

Bannister R (2003) The method of least squares to invert an orbit problem. Am J Phys 71:1268-1275

Barlow JF, Dunbar TM, Neimitz EG, Wood CR, Gallagher MW, Davies F, O'Connor E, Harrison RM (2011) Boundary layer dynamics over london, uk as observed using doppler lidar during repartee-ii. Atm Chem Phys 11:2111-2125

Beare RJ (2008) The role of shear in the morning transition boundary layer. Boundary-Layer Meteorol 129:395-410

Bouniol D, Illingworth A, Hogan R (2004) Deriving turbulent kinetic energy dissipation rate within clouds using ground based radar. In: Proceedings of $\operatorname{ERAD}(2004)$ 
Chai T, Lin CL (2004) Retrieval of microscale flow structures from high-resolution doppler lidar data using an adjoint model. J Atmos Sci 61:1500-1520

Cleugh HA, Grimmond CSB (2001) Modelling regional scale surface energy exchanges and cbl growth in a heterogeneous, urban-rural landscape. Boundary Layer Meteorology 98:1-31

Davis JC, Collier CG, Davies F, Bozier KE (2008) Spatial variations of sensible heat flux over an urban area measured using doppler lidar. Meteorol Appl $15: 367-380$

Deardorff JW (1970) Convective velocity and temperature scales for the unstable planetary boundary layer and for rayleigh convection. J Atmos Sci 27:1211-1213

Drennan WD, Zhang JA, French JR, McCormick C, Black PG (2007) Turbulent fluxes in the hurricane boundary layer. part ii: Latent heat flux. J Atmos Sci 64:1103-1115

Engelbart DAM, Kallistratova M, Kouznetsov R (2007) Determination of the turbulent fluxes of heat and momentum in the abl by ground-based remote-sensing techniques (a review). Meteorol Z 16:326-335

Gal-Chen T, Xu M (1992) Estimations of atmospheric boundary-layer fluxes and other turbulence parameters from doppler lidar data. J Geophys Res 97:409-423

Hogan R (2007) A variational scheme for retrieving rainfall rate and hail reflectivity fraction from polarization radar. J App Meteorol 46:1544-1564

Hogan RJ, Grant ALM, Illingworth AJ, Pearson GN, O'Connor EJ (2008) Vertical velocity variance and skewness in clear and cloud-topped boundary layers as revealed by doppler lidar. Q J R Meteorol Soc 135:635-643

Kaimal JC, Wyngaard JC, Haugen DA, Cote OR, Izumi Y, Caughey SJ, Readings CJ (1976) Turbulence structure in the convective boundary layer. J Atmos Sci 33:2152-2169

Lenschow DH, Wulfmeyer V (2000) Measuring second through fourth order moments in noisy data. J Atmos Ocean Tech 17:1330-1347

Lenschow DH, Wyngaard JC, Pennell WT (1980) Mean-field and second-moment budgets in a baroclinic, convective boundary layer. J Atmos Sci 37:1313-1326

Lenschow DH, Mann J, Kristensen L (1994) How long is long enough when measuring fluxes and other turbulence statistics. J Atmos Ocean Tech 11:661-673

Lenschow DH, Lothon M, Mayor SD, Sullivan PP, Canut G (2012) A comparison of higher-order vertical velocity moments in the convective boundary layer from lidar with in situ measurements and les. Bound-Lay Meteorol 143:107-123

Lorenc AC (1986) Analysis methods for numerical weather prediction. Q J R Meteorol Soc 112:1177-1194

Newsom RK, Banta RM (2004) Assimilating coherent doppler lidar measurements into a model of the atmospheric boundary layer. part i: algorithm development and sensitivity to measurement error. J Atmos Ocean Tech 21:1328-1345

O'Connor EJ, Illingworth AJ, Brooks IM, Westbrook CD, Hogan RJ, Davies F, Brooks BJ (2010) A method for estimating the turbulent kinetic energy dissipation rate from a vertically-pointing doppler lidar and independent evaluation from balloon-borne in-situ measurements. J Atmos Oceanic Technol 27:16521664

Pearson G, Davies F, Collier C (2009) An analysis of the ufam pulsed doppler lidar for observing the boundary layer. J Atmos Ocean Tech 26:240-250 
Rodgers CD (2000) Inverse Methods for Atmospheric Sounding. World Scientific Publishing

Roth M (2000) Review of atmospheric turbulence over cities. Q J R Meteorological Soc 26:941-990

33 Rudd AC, Robins AG, Lepley JJ, Belcher SE (2011) An inverse method for determining source characteristics for emergency response applications. Boundary Layer Meteorol 144:1-20

Rye BJ, Hardesty RM (1993) Discrete spectral peak estimation in incoherent backscatter heterodyne lidar. ii: Correlogram accumulation. IEEE Trans Geosci Remote Sens 31:28-35

Shutts GJ, Gray MEB (1994) A numerical modelling study of the geostrophic adjustment process following deep convection. Q J R Meteorological Soc 120:11451178

Sorbjan Z (1988) Local similarity in the convective boundary layer. Bound-Lay Meteorol 45:237-250

644 Sorbjan Z (1990) Similarity scales and universal profiles of statistical moments in the convective boundary layer. J Appl Meteorol 29:762-775

${ }^{44}$ Sorbjan Z (1991) Evaluation of local similarity functions in the convective boundary layer. J Appl Meteorol 30:1565-1583

48 Sullivan PP, Patton EG (2011) The effect of mesh resolution on convective boundary layer statistics and structures generated by large-eddy simulation. J Atmos Sci 68:8995-9005

51

Willmott CJ, Ackleson SG, Davis RE, Feddema JJ, Klink KM, Legates DR, O'Donnell J, Rowe CM (1985) Statistics for the evaluation and comparison of models. J Geophys Res 90:2395-2415

Young GS (1988) Turbulence structure of the convective boundary layer. part i: Variability of normalized turbulence statistics. J Atmos Sci 45:719-726 